\title{
What now for staff appraisals?
}

\section{James Goldman}

Associate Director of Advisory Services

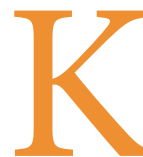

ey to the success of any

relationship is good

communication. Most

employment laws are aimed at

ensuring employer and employee talk about problems with a view to resolving them.

Whilst appraisals are not mandated, a regular look at the relationship the practice has with each member of staff is vital to keeping that relationship on track.

Perhaps that regular communication is all the more important as we come out of the Coronavirus lockdown and adapt to new ways of working. You need to ensure that your team know what they need to do and that they are doing it well.

More than that, staff will have been affected by COVID-19 in various ways. Some may be stressed about catching the virus, by money, childcare, or just by change. Some will have had to put their plans on hold. Others will be raring to go. Not only do your staff need to know about changes to the practice, but you need to know about changes to your staff.

It will be important to monitor how staff adapt to the changes, and how practice management adapts to changes in staff, and to take action where necessary.

So, whilst sitting down now to do appraisals with your staff seems a bad idea, you should ensure that you have discussions with staff to get go in the right direction now. And you should schedule a review in a few months' time to see how things are going.

\section{Discussions on reopening}

You should have a discussion with each member of staff on resumption of work. You will need to explain your plans to reopen, discuss the steps you are taking to ensure staff and patient safety, discuss your expectations from them. You will also need to ask them about their own situation, how they feel about returning, whether they have any concerns. If they do have concerns, listen to them carefully, see if they can be addressed. Both you and your employee should come out of that meeting with a clear understanding of what is expected.

If you have already reopened, but not had that discussion, then it is not too late to do so, see how things are going and discuss whether there are any expectations or objectives that still need to be set.

\section{Review}

After a few months you should have a meeting with each member of staff to see how they are performing and if there are any issues. Matters to discuss could include:

$\rightarrow$ How the staff member feels they are getting on since the practice reopened

$\rightarrow$ Whether the staff member feels the practice is operating safely for both patients and staff. Are there measures that the member of staff can think of that may help?

$\rightarrow$ How the member of staff is performing. This can include both the member of staff's view and the employer's

$\rightarrow$ Whether there is any further support the practice could give the member of staff

$\rightarrow$ How the practice has been doing, and what the plans are for the practice as we continue to move from lockdown

$\rightarrow$ How the member of staff can help the practice move forward

$\rightarrow$ Whether the member of staff has any personal issues relating to COVID-19, or anything else, that you should know about.

\section{More thorough appraisal}

As life in dentistry settles down from COVID-19, the practice can revisit its appraisal process. Choosing the right appraisal method is critical. It reflects what you think of your employees and how much you care about employee morale. Once you've chosen a review method for your needs, you should implement it properly to ensure it helps get the best performance from your dental team.

As dentists seek as much information to diagnose a problem with a tooth, including information from the patient, from an examination and radiograph, practices could obtain information from a variety of sources about members of staff. Information could come from:

$\rightarrow$ The employee's own view of their performance

$\rightarrow$ The practice owner or manager's view

$\rightarrow$ Staff providing feedback on each other. This may not work in every practice. But, if the practice can trust the staff to give constructive and helpful feedback, this could be useful

$\rightarrow$ Patient feedback. Some practices have patient feedback forms or call some patients after their treatment to ask how the patient felt about the service they received at the practice.

Using feedback from a variety of sources in this way increase staff awareness of how they perform and the impact it has on others, it highlights how to help individuals improve and can help to integrate performance feedback with work culture and promote engagement. But, leniency in review, cultural differences, competitiveness, ineffective planning, and misguided feedback all need to be avoided.

\section{Discussions with staff}

There are good ways and bad ways to discuss performance with staff. One place to start is by looking to career ambitions staff may have. Most will have some thoughts of where they want to go next. Or, if not, just asking the question lets staff know that you think they may be able to do more; and it prompts them to think about how they may want to develop.

Discuss with them which aspects of their job they see as an opportunity, and which they would rather not do. Help them to understand how doing the work they may not want to do can benefit them.

Look to see how you can drive members of your team to achieve better results and take on more complex tasks. See how you can support them to do so.

https://doi.org/10.1038/s41404-020-0448-y 